\title{
The value of routine antibiotic prophylaxis in mandibular third molar surgery: acute-phase protein levels as indicators of infection
}

\author{
Engin Bulut ${ }^{\S}$, Şule Bulut ${ }^{\dagger}$, Ílker Etikan ${ }^{\ddagger}$ and Osman Koseoglu ${ }^{\S}$

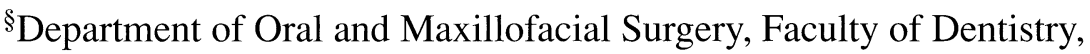 \\ University of Hacettepe, Ankara, Turkey \\ ${ }^{\dagger}$ Department of Periodontology, Faculty of Dentistry, University of Baskent, Ankara, Turkey \\ Department of Biostatistics, Faculty of Medicine, University of Hacettepe, Ankara, Turkey
}

(Received 27 November 2000 and accepted 24 April 2001)

\begin{abstract}
Postoperative infections in the oral region are usually caused by anaerobic bacteria. While some authors claim that routine antibiotic prophylaxis is necessary after third molar surgery, others do not recommend this practice. The major subject of controversy is what constitutes postoperative infection. Previous studies that have examined the benefit of routine antibiotic prophylaxis have used several clinical symptoms (pain, swelling, and trismus) as indicators of infection; however, these clinical symptoms may be vague and unreliable, and cannot be evaluated scientifically. As a result, their use has only sparked more debate in this area of research. The present study assessed the value of routine antibiotic prophylaxis in impacted mandibular third molar surgery using acutephase protein levels as potential indicators of early and late postoperative infection. Specifically, serum levels of C-reactive protein and alpha-1 antitrypsin were measured preoperatively and postoperatively in patients who received either prophylactic antibiotics or placebos. The results revealed no statistically significant difference between treated and control patients in terms of incidence of postoperative infection. (J. Oral Sci. 43, 117-122, 2001)
\end{abstract}

Key words: C-reactive protein; alpha-1 antitrypsin; antibiotic prophylaxis.

Correspondence to Dr. Engin Bulut, 2. Menekşe sokak no: 32/4 Kızılay 06440, Ankara TÜRKÍYE

E-mail address: aslibulut@mail.koc.net

\section{Introduction}

Pain, trismus, and swelling are the most common complications after surgical removal of impacted mandibular third molars. Although it is also an important problem, postoperative infection occurs less often, with an incidence of 1-10\% (1-4). Investigation has shown that these infections are correlated with type of impaction and the presence of preoperative infection (5).

The oropharynx normally harbors a complex population of microflora that includes more than 300 different bacterial species. Both aerobic and anaerobic microorganisms are present, and anaerobes outnumber aerobes by a factor of 10 to one (6). Knowing this, it would seem logical to administer prophylactic antibiotics to patients undergoing third molar surgery; however, the use of antibiotics for preventing wound infection in elective surgery is controversial. The operative site in third molar surgery is usually considered "clean-contaminated," a category for which prophylactic antibiotics are rarely indicated (7). In addition, antibiotic therapy is not without potential problems, and the benefits must be weighed against the risk of possible host reactions, such as anaphylaxis, sensitization, and drug toxicity (8). The development of antimicrobial resistance and secondary infections are other important risks of indiscriminate antibiotic therapy (9).

The literature contains arguments for and against the use of routine antibiotic prophylaxis in third molar surgery and the main source of controversy is the lack of reliable and sensitive clinical criteria for identifying postoperative infection in these patients. Some laboratory markers of 
infection have been used for this purpose, leukocytosis and erythrocyte sedimentation rate are the most common $(10,11)$ but these indicators are nonspecific in that they can be influenced by factors other than infection and they may not always signal when infection is present. For example, leukocytosis (a white cell count $>10,000 / \mathrm{mm}^{3}$ ) can arise due to several nonspecific factors, including strenuous exercise, certain forms of cardiac arrhythmia, and pregnancy (10). Also, in certain inflammatory and infectious states the leukocyte count may not be elevated, but instead may drop to below $4,000 / \mathrm{mm}^{3}$. The use of the erythrocyte sedimentation rate as an indicator of infection is limited after an inflammatory process has occurred because other elements, including red cell characteristics, serum protein and lipid levels, can affect sedimentation in complex ways (10).

The local tissue response to injury or infection is acute inflammation. The major clinical manifestations of this process reflect changes in vascular caliber and flow, increased vascular permeability, and attraction of leukocytes to the site. In addition to the local response, a vast number of systemic and metabolic changes occur (12). Alteration in serum levels of acute-phase proteins is a nonspecific response that is observed whenever inflammation is present (13); thus, elevation of any one or a combination of acutephase proteins can be diagnostic for infectious disease (11).

Serum levels of several acute-phase proteins rise in the setting of inflammation and tissue injury. As a group these proteins are heterogeneous, but they can be divided into two categories with respect to response times. One category includes C-reactive protein (CRP), the elevation of which can be detected within 6 hours of surgical trauma, and peaks at 24 to 48 hours $(10,14,15)$. CRP was first discovered by Tillett and Francis in 1930. It is synthesized by hepatocytes, and is normally present at trace levels in plasma $(10,15)$ and its significance in the assessment of acute infection and tissue destruction has been well documented. The production of this protein is triggered sensitively by disease activity, and it is a good indicator of response to therapy for inflammation, ischemia, and infection (14), but CRP levels do not rise in response to viral infections (16). Although there is no general agreement on what constitutes "normal" for CRP values, serum concentrations higher than $10 \mathrm{mg} / \mathrm{l}$ are generally considered to be pathologic $(14,15)$.

Alpha-1 antitrypsin (AT) is a member of the other category of acute-phase proteins, which are characterized by a delayed rise in serum levels $(10,17)$. This protein can be detected 12 to 24 hours after tissue injury, and peaks at 72 to 96 hours (10). AT was first identified by Schultze in $1955(17,18)$. It is synthesized by hepatocytes in a process regulated by inflammatory mediators such as interleukin-1, interleukin-6, tumor necrosis factor, and leukotrienes (19). Normal values for serum AT are 200$400 \mathrm{mg} / \mathrm{dl}$, and concentrations rise in a variety of infections and inflammatory conditions, producing a very wide range of abnormal values $(17,18)$. During inflammation and severe infection, the serum concentration of AT may rise to three times the normal level (20).

The purpose of this study was to evaluate the value of routine antibiotic prophylaxis for impacted mandibular third molar surgery using acute-phase protein levels as indicators of infection and response to therapy. A secondary aim was to determine whether serial quantitative determinations of the acute-phase proteins CRP and AT would assist in the monitoring of postoperative surgical cases, particularly in terms of detecting postoperative infection.

\section{Materials and Methods}

A clinical, two-way, double-blind, crossover study was conducted on 30 healthy out-patients ( 14 females and 16 males; mean age $23.7 \mathrm{yr}$; age range 20 to $28 \mathrm{yr}$; the surgeon and patients had no knowledge about the treatments). All the patients had impacted mandibular third molars surgically removed under local anesthesia at the Department of Oral Surgery, Hacettepe University Faculty of Dentistry. Patients with a doubtful medical history or acute infection were excluded. Each candidate was informed of the potential risks and benefits of the experimental procedure, and written consent was obtained from those who elected to participate. Subjects were enrolled based on the presence of bilaterally impacted third molars that were almost identical radiographically, and were estimated to be of equal surgical difficulty. A total of 60 impacted mandibular third molars were removed surgically, and each patient underwent two separate procedures, the second operation being carried out 4 weeks after the first. The same surgeon performed all operations.

Patients were assigned randomly to an experimental $(n=30)$ or control group $(n=30)$ and treated with either prophylactic amoxicillin trihydrate or a placebo. The experimental group received $1,000 \mathrm{mg}$ amoxicillin trihydrate at 8:00 a.m. (60 min prior to surgery), and 500 $\mathrm{mg}$ at 4:00 p.m. and 12:00 p.m. after surgery, then $500 \mathrm{mg}$ doses at the same times for the next four days. With the exception of an analgesic (paracetamol), the patients received no other medication during the experimental period. All operations were performed under local anesthesia with approximately $3.0 \mathrm{ml}$ of xylocaine containing adrenaline, and the duration of the operation was recorded. A buccal flap was raised at each surgical site using an envelope-type incision. In all cases, bone on the occlusal and buccal sides of the crown was removed 
with water-cooled burs. Complete closure of the wound was achieved with silk sutures.

Sterile venous blood samples were obtained from each subject prior to surgery and on postoperative days 1,3 , and 7. Each tube was centrifuged for $10 \mathrm{~min}$ at 2,500 rpm, and the serum samples were stored at $-20^{\circ} \mathrm{C}$ prior to analysis. The serum concentration of AT was determined by the radial-immunodiffusion method using nor-partigen immunodiffusion plates (Behringwerke A.G., Germany). Five microliters of serum was placed in each diffusion well, and the diameters of the precipitation rings were read after $48 \mathrm{~h}$ of diffusion at room temperature, using a scale provided by the manufacturer. The concentration of AT was then determined using the manufacturer's table of calibration values for nor-partigen immunodiffusion plates. According to the assay kit information, normal values for AT serum concentration range from 200 to $370 \mathrm{mg} / \mathrm{dl}$.

Serum CRP concentration was determined by rate immunonephelometry (automated immunochemistry system, Beckman Instruments Co., Fullerton, CA, USA). Quality control serum samples for low, normal, and high levels were included with each analytical run. In rate nephelometry, the antibody to a specific protein is added to a buffered solution of the patient's serum. The antigenantibody complexes that form are large enough to reflect light and can be observed with a nephelometer; the rate at which the complexes form can be tracked by the instrument's built-in computer. The results are compared internally against previously stored calibration data for the protein, and are then displayed. The upper, normal limit for CRP is $10 \mathrm{mg} / \mathrm{l}$.

The experimental and control group CRP and AT levels at the pre- and postoperative test times were analyzed statistically. The duration of surgery in each group was also

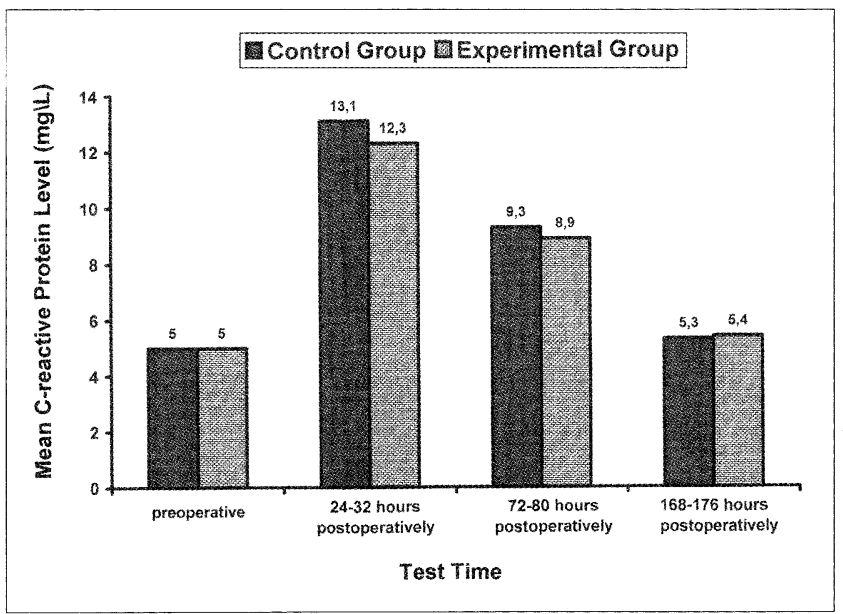

Fig. 1 Pre- and postoperative serum concentrations of Creactive protein in all subjects. analysed. Comparison within groups was done using the t-test for dependent samples, and groups were compared using the t-test for independent samples. Differences at $p \leq$ 0.05 were considered to be significant.

\section{Results}

There was no significant difference between the two groups in terms of duration of surgery (mean time 19 min), and both groups' preoperative CRP and AT values were within the normal range. Postoperative evaluation of serum CRP showed that levels in both groups had risen, peaked at 24-32 h, and then progressively declined to near normal by 7 days (Fig.1). When preoperative CRP concentrations were compared to the concentrations 24$32 \mathrm{~h}$ after surgery, there were significant differences in both the control and experimental groups $(\mathrm{tctr}=2.310, p=$ 0.028 and texp $=2.661, p=0.013$ ) but at $168-176 \mathrm{~h}$ after surgery, there was no significant difference for either group ( $\mathrm{t}_{\mathrm{ctr}}=1.213, p=0.235$ and texp $=0.474, p=0.639$ ). When comparisons were made between the two groups, the CRP levels were similar at each test time $(p>0.05)$.

As expected, the pattern of change in AT values differed from that of CRP, with AT serum levels peaking later (at $72-80 \mathrm{~h}$ ) in both the experimental and control groups (Fig.2). When preoperative AT concentrations were compared to levels at 72-80 h after surgery, the control and experimental groups both showed significant changes (tctr $=8.173, p=0.0001$ and $\operatorname{texp}=7.284, p=0.0001$ ); however, as with the CRP findings, there was no significant difference in either the control or the experimental group at 168-176 $\mathrm{h}(\mathrm{tctr}=0.449, p=0.657$ and $\operatorname{texp}=0.631, p=0.533$, respectively). When comparisons were made between the two groups, the AT levels were similar at each test time $(p>0.05)$.

Two subjects from each group developed postoperative infections, as identified by persistently elevated CRP values on postoperative day 3 (Table 1). The AT levels in these subjects were also extremely high at this stage (Table 2). Regardless of which group they were in, these patients were immediately changed to an antibiotic regimen of $600 \mathrm{mg}$ intravenous clindamycin every $12 \mathrm{~h}$ for 3 days. This treatment was deemed effective based on CRP and AT values, which returned to normal (Table 1,2). Based on the observed changes in serum concentrations of CRP and AT, the overall postoperative infection rate was $6.6 \%$ (2/30).

\section{Discussion}

Preoperative prophylactic antibiotics are used often in oral surgery practice, but it is not clear whether this is of any real benefit. Peterson's criterion for antibiotic use is 
that "the surgical procedure should have a significant risk of infection" (9). If the routine use of antibiotics for third molar surgery is to be recommended, this requirement must be met. As noted earlier, several other studies of complications associated with third molar surgery have indicated that the incidence of postoperative infections ranges from $1-10 \%$ (1-4). Considering this low figure, the routine use of antibiotics must be questioned.

What is the surgeon's motivation for using routine antimicrobial therapy when removing third molars? The logical answer is prevention of infection, since we know that after $12 \mathrm{~h}$ of fasting the mouth hosts large numbers of microorganisms, including streptococci, staphylococci, and a variety of anaerobic organisms (7). However, using antibiotic therapy without appropriate indications can have undesirable effects. Some of the risks of indiscriminate antibiotic therapy include the development of microbial resistance, secondary infections, drug toxicity, and allergic reactions (9). It is estimated that $6-7 \%$ of patients on antibiotics experience some form of adverse reaction (9). The benefits of antibiotic therapy in the asymptomatic patient must exceed the risk of undesirable outcomes.

Many investigators have assessed the efficacy of antibiotics in reducing morbidity, and most reports in the literature have focused on decreasing the incidence of alveolar osteitis and diminishing the severity of pain, trismus, and postoperative edema. The results suggest that an aseptic surgical site and careful surgical technique to minimize trauma are of utmost importance in reducing these

Table 1 Pre- and postoperative serum concentrations of Creactive protein in the patients who developed infection

\begin{tabular}{|c|c|c|c|c|c|c|c|c|}
\hline & \multicolumn{2}{|c|}{$\begin{array}{c}\text { PREOPERATIVE } \\
\text { DAY }\end{array}$} & \multicolumn{2}{c|}{$\begin{array}{c}\text { POSTOPERATIVE } \\
24-32\end{array}$} & \multicolumn{2}{c|}{$\begin{array}{c}\text { POSTOPERATIVE } \\
72-80 \text { HOURS }\end{array}$} & \multicolumn{2}{|c|}{$\begin{array}{c}\text { POSTOPERATIVE } \\
168-176 \text { HOURS }\end{array}$} \\
\hline No & Ctrl. Group & Exp. Group & Ctrl. Group & Exp. Group & Ctrl. Group & Exp. Group & Ctrl. Group & Exp. Group \\
\hline 1 & $5 \mathrm{mgLL}$ & $5 \mathrm{mgLL}$ & $35 \mathrm{mgL}$ & $31 \mathrm{mgLL}$ & $40 \mathrm{mgL}$ & $35 \mathrm{mgL}$ & $8 \mathrm{mgL}$ & $6 \mathrm{mglL}$ \\
\hline 2 & $5 \mathrm{mgL}$ & $5 \mathrm{mgL}$ & $32 \mathrm{mgL}$ & $33 \mathrm{mgL}$ & $37 \mathrm{mgL}$ & $36 \mathrm{mgL}$ & $7 \mathrm{mgL}$ & $9 \mathrm{mgL}$ \\
\hline
\end{tabular}

Ctrl. Group : Placebo-treated control patients

Exp. Group: Antibiotic-treated patients

Table 2 Pre- and postoperative serum concentrations of alpha-1 antitrypsin in thepatients who developed infection

\begin{tabular}{|c|c|c|c|c|c|c|c|c|}
\hline \multirow[b]{2}{*}{ No } & \multicolumn{2}{|c|}{$\begin{array}{l}\text { PREOPERATIVE } \\
\text { DAY }\end{array}$} & \multicolumn{2}{|c|}{$\begin{array}{c}\text { POSTOPERATIVE } \\
\text { 24-32 HOURS } \\
\end{array}$} & \multicolumn{2}{|c|}{$\begin{array}{c}\text { POSTOPERATIVE } \\
\text { 72-80 HOURS } \\
\end{array}$} & \multicolumn{2}{|c|}{$\begin{array}{c}\text { POSTOPERATIVE } \\
\text { 168-176 HOURS } \\
\end{array}$} \\
\hline & Ctrl. Group & Exp. Group & Ctrl. Group & Exp. Group & Ctrl. Group & Exp. Group & Ctrl. Group & Exp. Group \\
\hline 1 & $223 \mathrm{mgldL}$ & $212 \mathrm{mgldL}$ & $298 \mathrm{mgldL}$ & $260 \mathrm{mgldL}$ & $411 \mathrm{mgldL}$ & $366 \mathrm{mgldL}$ & $272 \mathrm{mgldL}$ & $235 \mathrm{mgldL}$ \\
\hline 2 & $235 \mathrm{mgldL}$ & $248 \mathrm{mgldL}$ & $272 \mathrm{mgldL}$ & $285 \mathrm{mgldL}$ & $387 \mathrm{mgldL}$ & \begin{tabular}{|l|}
399 mgldL \\
\end{tabular} & $248 \mathrm{mgldL}$ & $260 \mathrm{mgldL}$ \\
\hline
\end{tabular}

Ctrl. Group: Placebo-treated control patients

Exp. Group: Antibiotic-treated patients negative outcomes in third molar surgery (9). Several studies have examined the preventive use of antibiotics for this procedure, but few have compared the incidences of infection in patients who are antibiotic-treated and those who are placebo-treated.

Happonen et al. evaluated the use of prophylactic penicillin and tinidazole for third molar surgery in a randomized, double-blind, placebo-controlled clinical trial (21). They reported no difference between antibiotic and placebo treatment in terms of outcome, and concluded that neither penicillin nor tinidazole provided any benefit as a prophylactic therapy. In another well-designed, prospective, randomized, double-blind study, Curran et al. also investigated the incidence of infection in oral-surgery patients who received or did not receive antibiotic therapy (22). These authors found no justification for using routine antibiotics for third molar surgery. In contrast, Mitchell and Morris compared tinidazole with a placebo for preventing infection after third molar removal, and found a significantly lower incidence of infection in the tinidazole group (23). However, since the definition of infection in that study was "alveolar osteitis," it is impossible to determine which patients actually had true postoperative infections and which had simple alveolar osteitis. Based on their findings, Mitchell and Morris recommended the use of an anaerobicidal drug for patients undergoing surgery for bony impacted third molars, but problems with the authors' methodology and their criteria for determining infection detract from the strength of this conclusion.

The present study explored the issue of prophylactic antibiotic therapy in third molar surgery by examining serum concentrations of CRP and AT as possible markers of early and late postoperative infection. In all patients, CRP levels rose from the baseline to maximum levels within 24-32 h of surgery (Fig.1). This elevation may be attributed to surgery-induced aseptic traumatic inflammation. Despite this inflammation, with the exception of two subjects from each group, all patients' CRP values remained within the normal range. In the four patients who had evidence of postoperative infection, the postoperative serum CRP levels remained elevated until the infection was effectively treated (Table 1). This finding indicates that serum CRP measures can be used for early detection of bacterial infections, and that these levels are also useful for monitoring the clinical course of patients who undergo surgery for removal of impacted mandibular third molars.

The serum concentrations of AT reached maximum levels at $72-80 \mathrm{~h}$ in the treated and control groups, and then decreased to baseline values over 1 week (Fig.2). With the exception of two subjects from each group, all patients' 
AT values remained within the normal range. The AT levels in the four subjects with infections also peaked at $72-80 \mathrm{~h}$ and reached very high values, but they began to fall after the antibiotic regimen was changed (Table 2). Determination of AT serum levels provided no information that would assist in monitoring early postoperative infections; however, serum concentrations of this protein may be useful for evaluating late postoperative infection and chronic inflammatory conditions after third molar surgery.

This investigation revealed no statistically significant differences between the group that received antibiotic prophylaxis and the placebo-treated group with regard to changes in serum levels of CRP and AT at each time of sampling. According to the measurements of acute-phase protein levels, the overall postoperative infection rate in the treated and control patients was $6.6 \%$.

In summary, these findings prove that routine antibiotic prophylaxis is not always indicated or beneficial in patients who undergo surgery for removal of impacted mandibular third molars. This form of treatment should not be used in every case. Regarding acute-phase protein levels, serum CRP concentrations may be useful for early detection of bacterial infection and for monitoring the clinical course in patients who undergo third molar surgery. In contrast, AT levels yield no information about early postoperative infections but might be useful for evaluating late postoperative infection and chronic inflammatory conditions after third molar surgery.



Fig. 2 Pre- and postoperative serum concentrations of alpha1 antitrypsin in all subjects.

\section{References}

1. Goldberg, M.H., Nemarich, A.N. and Marco, W.P. II. (1985) Complications after mandibular third molar surgery: a statistical analysis of 500 consecutive procedures in private practice. $\mathrm{J}$. Am. Dent. Assoc. 111, 277-279

2. Hochwald, D.A., Davis, W.H. and Martinoff, J. (1983) Modified distolingual splitting technique for removal of impacted mandibular third molars: incidence of postoperative sequelae. Oral Surg. Oral Med. Oral Pathol. 56, 9-11

3. Osborn, T.P., Frederickson, G.J., Small, I.A. and Torgerson, T.S. (1985) A prospective study of complications related to mandibular third molar surgery. J. Oral Maxillofac. Surg. 43, 767-769

4. Sisk, A.L., Hammer, W.B., Shelton, D.W. and Joy, E.D. Jr. (1986) Complications following removal of impacted third molars: the role of experience of the surgeon. J. Oral Maxillofac. Surg. 44, 855-859

5. MacGregor, A.J. and Hart, P. (1969) Effect of bacteria and other factors on pain and swelling after removal of ectopic mandibular third molars. J. Oral Surg. 27, 175-179

6. Borthen, L., Heimdahl, A. and Nord, C.E. (1987) Selective suppression of the anaerobic oropharyngeal microflora with local metronidazole. Br. J. Oral Maxillofac. Surg. 25,49-56

7. Conover, M.A., Kaban, L.B. and Mulliken, J.B. (1985) Antibiotic prophylaxis for major maxillocraniofacial surgery. J. Oral Maxillofac. Surg. 43, 865-869

8. Gallagher, D.M. and Epker, B.N. (1980) Infection following intraoral surgical correction of dentofacial deformities: a review of 140 consecutive cases. J. Oral Surg. 38, 117-120

9. Zeitler, D.L. (1995) Prophylactic antibiotics for third molar surgery: a dissenting opinion. J. Oral Maxillofac. Surg. 53, 61-64

10. Fischer, C.L., Gill, C., Forrester, M.G. and Nakamura, R. (1976) Quantitation of "acute-phase proteins" postoperatively. Value in detection and monitoring of complications. Am. J. Clin. Pathol. 66, 840-846

11. Kenny, R.A., Hodkinson, H.M., Cox, M.L., Caspi, D. and Pepys, M.B. (1984) Acute phase protein response to infection in elderly patients. Age Ageing 13, 89-94

12. Kushner, I. (1982) The phenomenon of the Acute Phases Responses. In C-reactive protein and the plasma protein response to tissue injury. Kushner, I., Volanakis, J.E. and Gewurz, H. eds., Ann. N.Y. Acad. Sci. 389, 39-48

13. Clarke, H.G., Freeman, T. and Pryse-Phillips, W. (1971) Serum protein changes after injury. Clin. 
Sci. 40, 337-344

14. Aalto, K., Österman, K., Peltola, H. and Rasanen, J. (1984) Changes in erythrocyte sedimentation rate and C-reactive protein after total hip arthroplasty. Clin. Örthop. 184, 118-120

15. Pepys, M.B. (1981) C-reactive protein fifty years on. Lancet 21, 653-657

16. Stahl, W.M. (1987) Acute phase protein response to tissue injury. Crit. Care Med. 15, 545-550

17. Arvillommi, H. (1972) Studies on serum Pi- and C3polymorphism in Finland. Acta Pathol. Microbiol. Scand. (B) Suppl. 234, 9-20

18. Breit, S.N. and Penny, R. (1980) The role of alpha1 protease inhibitor (alpha-1 antitrypsin) in the regulation of immunologic and inflammatory reactions. Aust. N.Z. J. Med. 10, 449-453

19. Wannfors, K. and Hasson, L.O. (1991) Plasma protein changes in chronic osteomyelitis of the jaws. J. Oral. Pathol. Med. 20, 81-85

20. Peterson, R.J. and Marsh, C.L. (1979) The relationship of alpha 1 antitrypsin to inflammatory periodontal disease. J. Periodontol. 50, 31-35

21. Happonen, R.P., Backström, A.C. and Ylipaavalniemi, P. (1990) Prophylactic use of phenoxymethylpenicillin and tinidazole in mandibular third molar surgery, a comparative placebo controlled clinical trial. Br. J. Oral Maxillofac. Surg. 28, 1215

22. Curran, J.B., Kennett, S. and Young, A.R. (1974) An assessment of the use of prophylactic antibiotics in third molar surgery. Int. J. Oral Surg. 3, 1-6

23. Mitchell, D.A. and Morris, T.A. (1987) Tinidazole or pivampicillin in third molar surgery. Int. J. Oral Maxillofac. Surg. 16, 171-174 